\section{Professional Meeting and Workshop on Research and Innovation at the Faculty of Transport and Traffic Sciences}

The Committee on Science and Projects of the Faculty of Transport and Traffic Sciences organized professional meeting and workshop on internal Program for stimulation of research and innovation. The meeting and workshop were held on 1 February 2017 at the Faculty.

Within the Faculty's strategic framework to develop and innovate scientific activities the Program for stimulation of research and innovation started in 2015. The program emphasis was on the outcomes of scientific research (impact of scientific activities on certain segments of society and the economy), and the outputs in the form of research results.

Science and research in all areas are oriented towards research groups and networks. Education, research, and innovation are characterised by a strong flow of knowledge, introduction of research results and innovation practice into education, strong partnerships and intellectual property management. New ideas and knowledge, new processes, products and services, and new entrepreneurship are the ingredients of investigative creativity.

The results from fifteen research groups were presented in the forms of technical reports and posters. Here are some basic features of each presented project:

Drivers visual detective evaluation and impact on road safety (Assist.Prof. Darko Babić, Ph.D.). The process of driver's perception of traffic signs was analyzed using sophisticated eye tracking system, in simulated and real-life traffic conditions. The results lead to the conclusion that the examinees focus much more on signs they do not understand because they are trying to understand their meaning.

Research of measures to improve safety at level crossings (Assist.Prof. Danijela Barić, Ph.D.). The research included a number of activities with the aim of establishing an interdisciplinary research group that will be continuously and long-term dealing with research in the field of safety at level crossings and prevention measures.

Development of research capacities in the field of applied aerodynamics (Assist.Prof. Anita Domitrovic, Ph.D.). Research contributed to the development of wind tunnel measurement systems and raising the competitiveness of research groups in the field of applied aerodynamics.

Possibilities of applying information and communication technologies and services in the function of carpooling systems (Assist.Prof. Ivan Grgurević, Ph.D.).
The contribution of the project is reflected in the determination of relevant factors of applicable technologies for the needs of carpooling development as an alternative and sustainable transportation mode.

Navigation of electric vehicles with the criteria of minimal energy consumption (Assist.Prof. Edouard Ivanjko, Ph.D.). Goal of the project was to build a small scale electric vehicle and to start the development of a simulation model for small scale electric vehicle and of new routing algorithms.

Development of air traffic management research centre (Assist.Prof. Biljana Juričić, Ph.D.). The main focus of this project was to gather scientists and young researchers around air traffic control management topic with the goal of improving and increasing air traffic efficiency.

Distributed flight control system simulator for aircraft autostabilization (Karolina Krajček Nikolić, Ph.D.). The main point of this project is to decentralize the flight control system in a way to locate the microprocessors near the flight control surfaces that would enable reduction of mass and simplification of the control system and architecture.

Trans European public transport regional innovative strategy (Luka Novačko, Ph.D.). Project responses to the current challenges in terms of public transport planning and coordination, and the tool that enables stakeholders to collect data necessary to manage the regional connections was designed and evaluated.

System of automatic identification and informing of mobile entities in the traffic environment (Assist. Prof. Marko Periša, Ph.D.). The aim of the research was to define a new value chain of delivery for service of mobile traffic entities identification and new service of informing for traffic system users.

Robust navigation systems for UAVs (Tomislav Radišić, Ph.D.). The project is aimed at determining weak points in the currently used navigation systems for small and micro UAVs, finding appropriate solutions and testing them in flight.

The survey of business conditions of the Croatian carriers in public road passenger and freight transport - areas of cooperation with the Faculty of Transport and Traffic Sciences (Prof. Marijan Rajsman, Ph.D.). The goal of the project was to increase the engagement and visibility of the Faculty and maximize the contribution of the social environment through mutual interaction with carriers.

Identification of parcel logistic flows in the city of Zagreb city logistics (Tomislav Rožić, Ph.D.). The project analysed trends in distribution and parcel returns and their share in total logistics goods flow within the area.

Cognitive approach to the ergonomic assessment of factors from the group human factor of traffic participants (Assist.Prof. Davor Sumpor, Ph.D.). This project explored how the factors of permanent and/or 


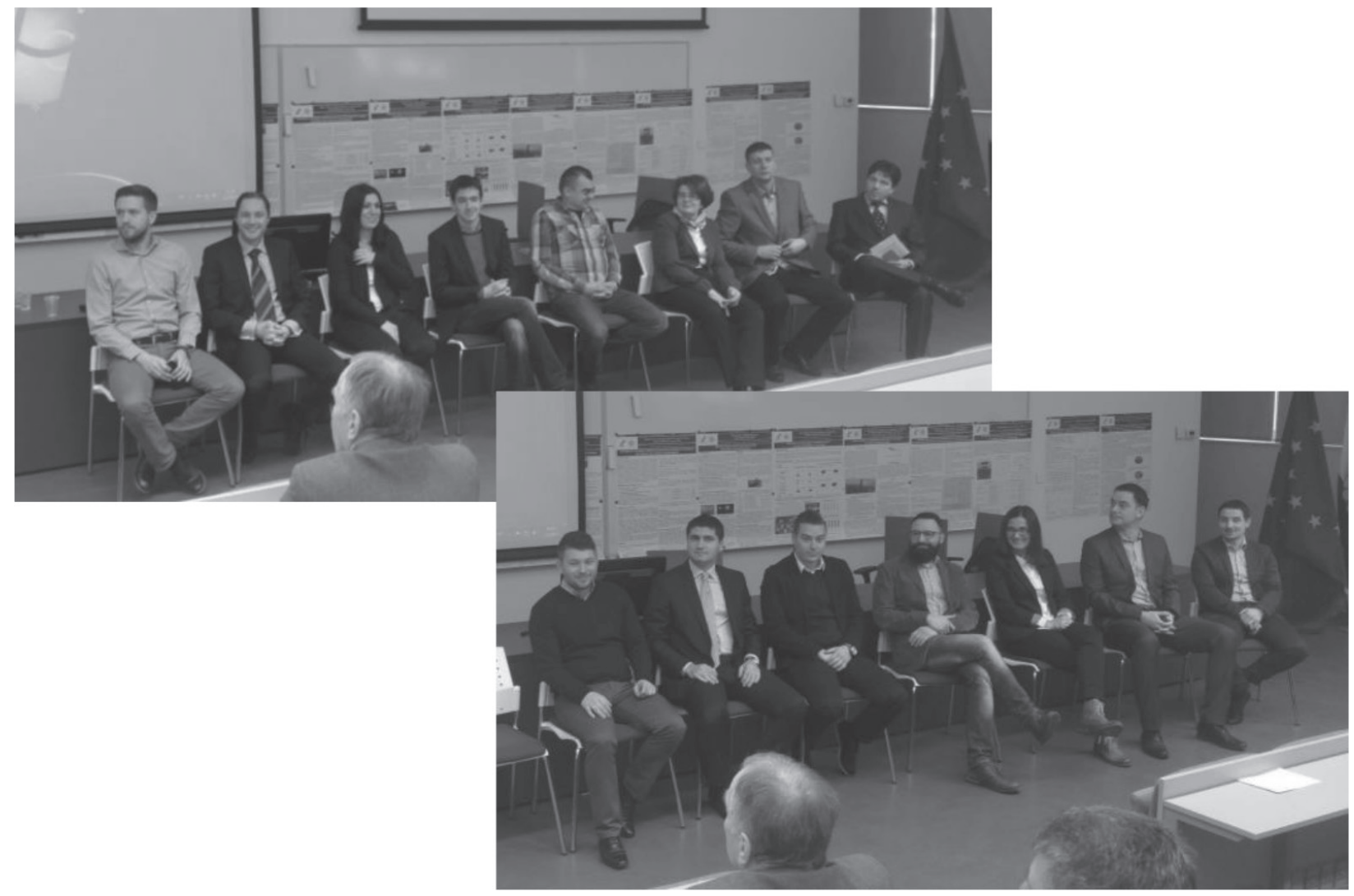

Presenters of the projects at the professional meeting and workshop

temporary disturbance from the working and/or traffic environment may negatively affect the factors from the group human factor.

Research on the safe application of contemporary information and communications equipment in traffic entities (Željko Šarić, Ph.D.). The goal of the research was to determine the safety aspects of the application of mobile terminal devices in the traffic environment and evaluate their impacts through the reaction time.

Organization of HEMS operations in the Republic of Croatia (Prof. Andrija Vidović, Ph.D.). In this project,
HEMS operations are theoretically defined; technical and technological helicopter features and equipment used for medical flights are described; and proposition of organizational structure of helicopter emergency medical services in the Republic of Croatia is given.

The Faculty will continue to encourage the development and innovative character of scientific activities, with emphasis on the outcomes it terms of impact of scientific activities on specific segments of transport and traffic technology.

Assoc. Prof. Doris Novak, Ph.D.

Chairman of the Committee on Science and Projects Faculty of Transport and Traffic Sciences University of Zagreb 